\title{
Perceived discrimination and psychosis: a systematic review of the literature
}

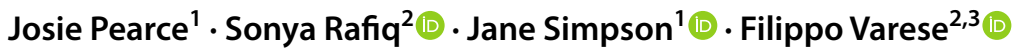

Received: 27 November 2018 / Accepted: 13 May 2019 / Published online: 24 June 2019

(c) The Author(s) 2019

\begin{abstract}
Purpose Higher rates of psychosis have been reported in minority groups. Since individuals belonging to such groups are vulnerable to the experiences of discrimination, and in line with models proposing that social and life adversity may play a causal role in development and maintenance of psychotic experiences, it has been proposed that perceived discrimination may represent an important determinant of psychotic experiences. This paper reviews the literature examining the relationship between perceived discrimination and psychosis, examining whether discrimination is associated with an increased risk of psychosis, the severity of psychotic symptoms and whether there is an association with specific psychotic symptoms. Methods A systematic database search of PsycINFO, Embase and PubMed was conducted to identify quantitative crosssectional and prospective studies that examined the association between discrimination and psychosis.

Results Twenty-four studies met the inclusion criteria, four of which used prospective designs and twenty used cross-sectional designs. The main findings indicated that discrimination may be associated with an increased risk of psychosis (too few studies to determine whether discrimination is associated with severity). Some studies found associations between discrimination and positive psychotic experiences and/or specific psychotic experiences such as paranoia. A small number of studies found that greater exposure to discrimination was associated with a greater likelihood of reporting psychotic experiences, tentatively indicating a dose-response relationship.

Conclusions This review indicates that discrimination plays an important role in the experience of psychosis; however, future research is required to clarify the nature of this relationship. Avenues for further research and clinical implications are proposed.
\end{abstract}

Keywords Perceived discrimination · Trauma $\cdot$ Minority $\cdot$ Psychosis

\section{Introduction}

Higher rates of psychosis have been consistently found among minority groups such as immigrants, ethnic minorities and non-heterosexual individuals [1-3]. Research

Filippo Varese

filippo.varese@manchester.ac.uk

1 Division of Health Research, Faculty of Health and Medicine, Lancaster University, Lancaster, UK

2 Division of Psychology and Mental Health, School of Health Sciences, Faculty of Biology, Medicine and Health, Manchester Academic Health Sciences Centre, University of Manchester, Manchester, UK

3 Complex Trauma and Resilience Research Unit, Greater Manchester Mental Health NHS Foundation Trust, Manchester, UK suggests that belonging to a minority group increases the risk of experiencing psychosis [2-7]. Although a variety of possible mechanisms have been proposed to explain the excess risk of psychosis in specific minority groups, these explanations have been largely specific to ethnic minorities. In studies focusing on immigration status, it has been argued that pre-migration factors or the experience of migration itself cannot explain the increased risk of psychosis, as the incidence rates for first- and second-generation immigrants are on average similar [5]. Ethnic minorities who have not experienced migration are also at greater risk [3] and more visible minorities have a higher risk of psychosis [5, 6]. The effect of ethnic minority status on psychosis risk is dependent on ethnic density (the greater the proportion of an ethnic minority in the population, the lower the risk) [8,9]. In light of this evidence, the degree to which a person is a minority, or stands out as a minority, in relation to the wider social 
environment may be an important factor. In recent socialdevelopmental models of the development of psychosis, context-specific stressors, such as discrimination [unfair treatment or negative attitudes towards different categories (age, gender, race, religion, disability, sexual orientation) of people], are assumed to contribute to the elevated risk for psychosis observed in minority groups [10]. Discrimination as a mechanism involved in the pathway between minority status and psychosis liability would also account for the increased risk observed across diverse minority groups, as discrimination is one common experience that most minority groups share [11].

Given the negative impact of discrimination on a wide range of social, physical and mental health outcomes [2, 12], it has been proposed that discrimination may also play a role in the development of psychosis, particularly in light of the robust and increasingly large evidence base linking other adverse experiences to an increased risk for psychosis and/or exacerbation of the severity of psychotic symptoms $[12,13]$. Such adverse experiences include bullying, social inequality and neglect $[12,14]$, all of which share common experiences of discrimination including social threat, deprivation of resources and unfair treatment.

The potential role of discrimination in conferring vulnerability for psychosis is plausible in the light of several theoretical proposals, including the social defeat model. This model highlights how being in a subordinate, 'outsider' position within one's social environment can induce prolonged threat and chronic stress [15], potentially leading to the sensitization of the mesolimbic dopamine system and the dysregulation of the hypothalamic-pituitary-adrenal axis, and these changes are thought to be associated with a range of mental health difficulties, including psychosis [15-17]. Discrimination also shares similar experiences with social inequality, a construct that has been linked to negative physical and mental health outcomes [18-23], including the risk of psychosis [6, 24]. Research suggests that the impact of social inequality cannot be explained by deprivation alone [25, 26]; rather it is the relativity of deprivation in which inequality is present that promotes adverse outcomes [27]. Although research into the impact of social inequality on psychosis is in its infancy, evidence suggests that it may explain the relationship between deprivation and psychotic symptoms, in particular, paranoia [14]. The potential importance of discrimination is also consistent with a cognitive model of psychosis proposed by, for example, Garety et al. [28] suggesting that chronic experiences of power imbalance, threat and social humiliation can lead to the development of negative schemas (beliefs) about the self and others, which are often elevated in people with psychosis and are believed to fuel the development of psychosis. Since discrimination involves social threat and humiliation, it is plausible that this may influence the development of negative schematic beliefs, and cognitive models suggesting that chronic experiences of discrimination and negative schema may increase paranoid attributional styles, a theory that is supported by empirical evidence [29]. This may suggest that discrimination could be more strongly associated with paranoia (which involves mistrust or fear of others, perceptions of persecution and anticipation of threat) than with other psychotic experiences. These parallel research findings showing that deprivation predicts paranoia but not hallucinations [14] and that living in urban areas in which powerlessness and victimisation are experienced increases the risk of paranoia [30].

In light of the theoretical and empirical evidence cited above, the aims of the review were threefold. First, findings were reviewed from studies to examine whether perceived discrimination might be more prevalent in service users with psychosis and individuals reporting psychotic experiences relative to controls. Second, the review examined whether discrimination was associated with more severe clinical presentations. Third, in light of tentative proposals suggesting that exposure to discrimination may increase proneness to paranoid experiences, the review specifically intended to investigate the associations between minority discrimination and specific psychotic experiences.

\section{Method}

\section{Inclusion and exclusion criteria}

This systematic review was carried out in accordance with the Preferred Reporting Items for Systematic Reviews and Meta-Analyses (PRISMA) standards [31]. Studies that met the following criteria were included in the review: (1) quantitative analyses examining the cross-sectional and/or longitudinal relationship between perceived discrimination and psychosis; (2) studies employing validated diagnostic/ dimensional measures of clinical or non-clinical experiences of psychosis; and (3) reports written in English. Studies were excluded if: (1) the type of discrimination measured was related to mental health (e.g., stigma related to diagnosis, unfair treatment related to mental health difficulties); (2) they were presented in a conference extract or single case study format; or (3) participants had a primary diagnosis of substance-induced psychosis or psychosis secondary to organic pathology. No restrictions were placed on the measurement of perceived discrimination used in terms of validity or reliability.

\section{Search strategy}

Studies were reviewed up to and including the 14th of December 2017. Specifically, PsycINFO, Embase and PubMed were systematically searched using the following 
search string (discrimination OR discriminated OR victimi* OR prejudic* OR inequality OR homophob* OR sexualism OR racism OR racist OR racial OR sexis* OR ageis* OR disablism OR unfair treatment) AND (hearing voices OR voice hearing OR hallucinat* OR delusion* OR paranoid OR paranoia OR psychotic OR psychosis OR schizophren* OR 'severe mental' OR 'serious mental'). Eligibility was established in three stages: title, abstract, and full-article screening. Backward and forward searches of eligible papers were performed to identify additional studies. Figure 1 displays the PRISMA flowchart that details the systematic search and screening process.
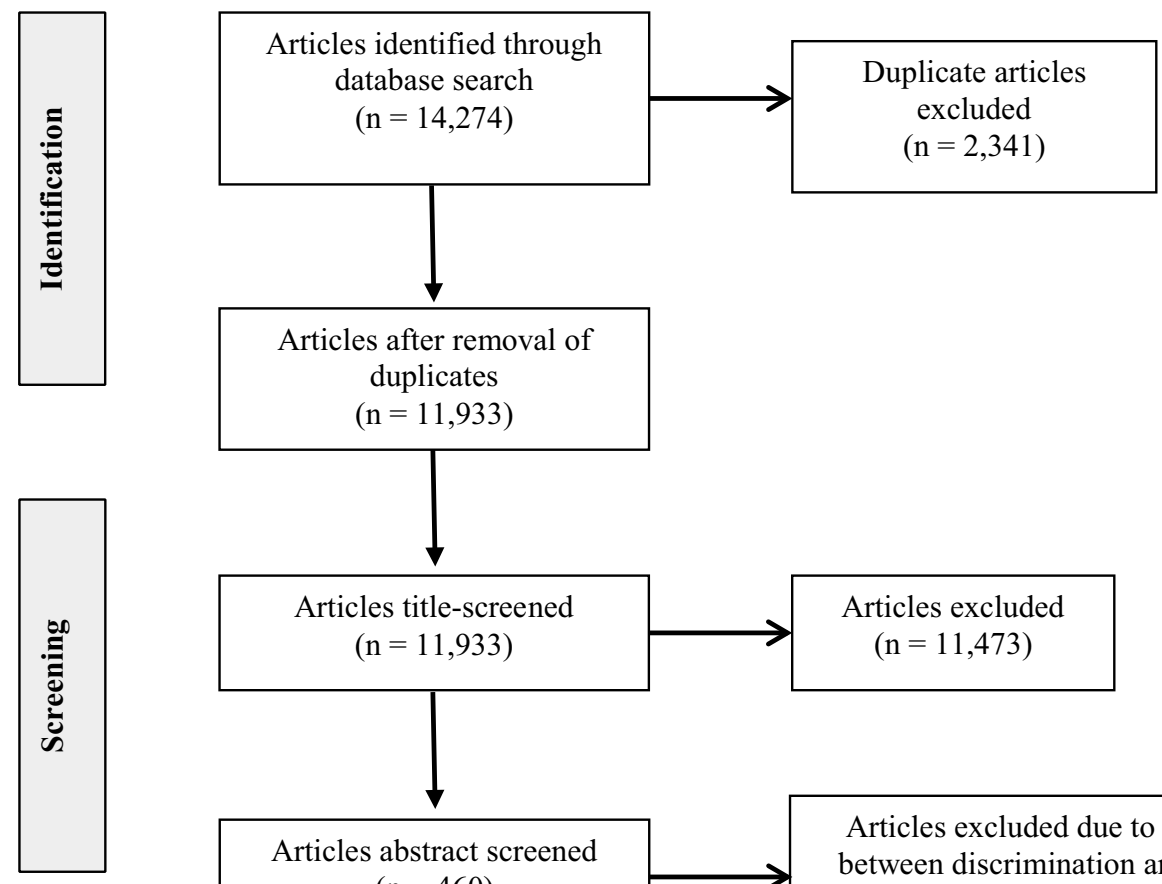
$(\mathrm{n}=2,341)$

Articles after removal of duplicates

$(\mathrm{n}=11,933)$
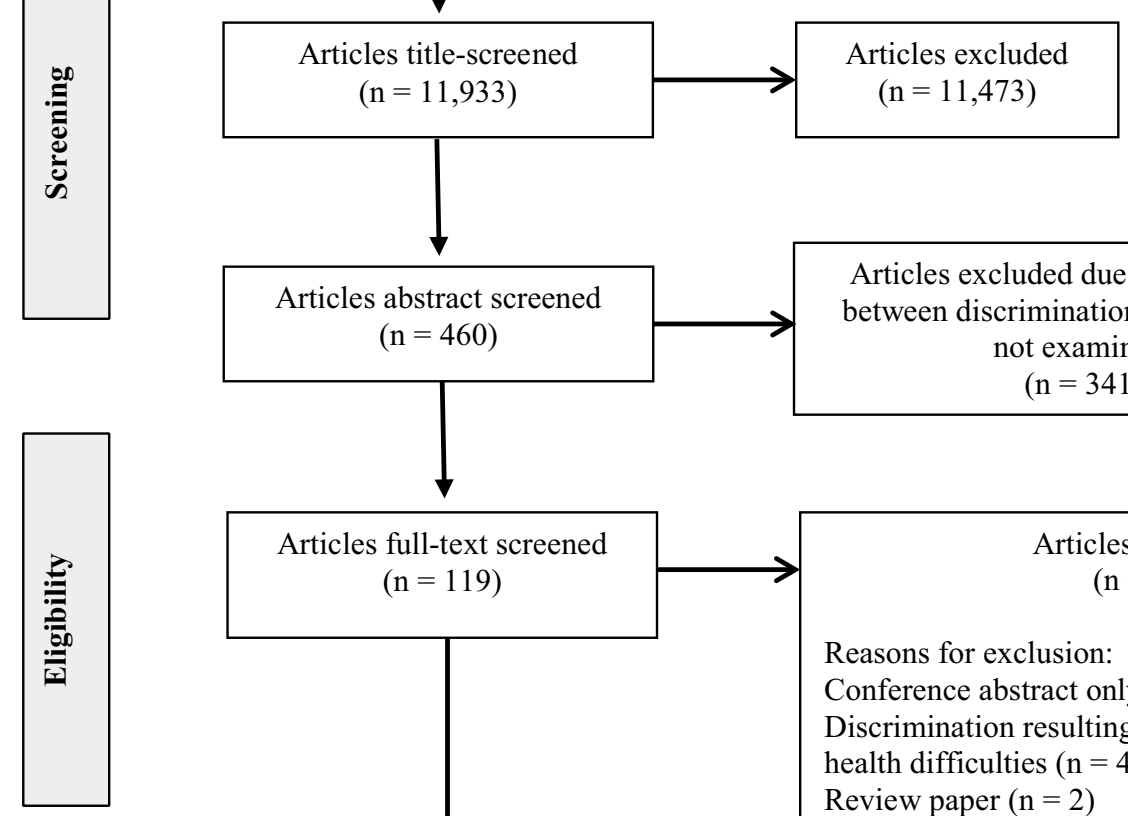

Articles excluded due to relationship between discrimination and psychosis not examined:

$$
\begin{aligned}
& \text { not examined: } \\
& \qquad(\mathrm{n}=341)
\end{aligned}
$$

\section{Articles excluded}

$$
(\mathrm{n}=97)
$$

Reasons for exclusion:

Conference abstract only $(n=3)$

Discrimination resulting from psychosis/ mental health difficulties $(n=42)$

Review paper $(\mathrm{n}=2)$

No psychosis outcome $(n=23)$

Relationship between discrimination and psychosis not examined $(\mathrm{n}=13)$

No discrimination measure $(\mathrm{n}=12)$

Language other than English $(n=1)$

Un-retrievable studies $(\mathrm{n}=1)$

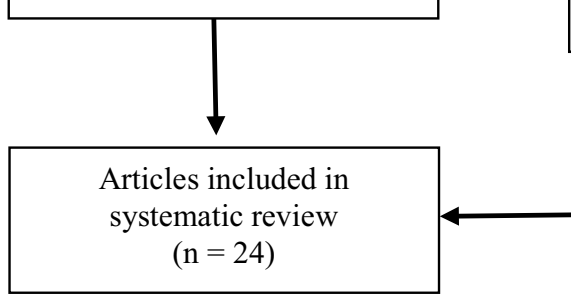

Backward and forward screening $(\mathrm{n}=2)$

Fig. 1 Flowchart of studies included in review 


\section{Quality assessment}

Eligible studies were quality assessed using the Effective Public Health Practice Project tool (EPHPP [32]). This tool assesses quality in observational, cross-sectional, longitudinal studies, and presents good validity and inter-rater reliability [32,33]. Each study was assessed on selection bias, study design, confounding variables, blinding, data collection and attrition. Given the ambiguity surrounding the assessment of confounding variable component, if the primary studies controlled for variables found to influence the relationship between psychosis and discrimination (e.g., age, sex, ethnicity, socioeconomic status; [9, 11]), different ratings were given. For example, if age and sex were controlled for, it was only assumed less than $60 \%$ of the relevant confounders were controlled for. EPHPP guidelines also suggest giving each study a global quality rating (weak, moderate, and strong) based on components. However, global ratings were not provided in this review, as they may mask and mislead the quality appraisal of included studies [34]. Additionally, studies were quality assessed by two researchers. S.R assessed all studies, and J.P examined 60\%. Disagreements were resolved by consultations with F.V.

\section{Results}

As shown in Fig. 1, 24 eligible studies were identified. Table 1 provides a summary of the study characteristics and research findings of each study, grouped according to discrimination type: clinical and non-clinical samples.

\section{Sample and design characteristics of eligible studies}

Of the 24 eligible studies, 8 were carried out in the UK, 4 in the Netherlands, 11 in the USA, and 1 in Norway. A total of 35,726 participants took part in the studies included in the review (regarding overlapping samples, the studies considering the largest sample sizes were included in the total). Four of the studies involved clinical samples $(n=1017)[9$, $35-37]$ and the remaining twenty recruited from non-clinical populations $(n=34,709)$ [11, 38-56]; thirteen used eight different epidemiological samples (AESOP, EMPIRIC, Fourth National Survey of Ethnic Minorities, MEDINA, NAPLS 2, NEMESIS, NSLASS and NSAL). Within the twenty studies that reported the sex of the participants, $53 \%$ were female (regarding overlapping samples, the studies considering the largest sample sizes were included in the total).

The studies examined the relationship between different types of discrimination and psychosis. Twelve studies examined racial discrimination $[9,11,35,36,38-43,55$,
56]; one examined race/cultural or religious discrimination [37], religious discrimination [46], gender discrimination [44], and discrimination based on sexual orientation [45]. Three examined racial/religious discrimination [47-49]; the remaining measured a range of discriminatory experiences requesting participants to attribute them to various factors including age, sex, sexual orientation, ethnicity, disability, skin colour, religion and appearance [50-54]. The clinical studies included in the review examined the impact of discrimination across the continuum of psychosis, including individuals at a clinical high risk of developing psychosis [43, 52, 53], first-episode psychosis [37] and people experiencing long-term psychosis $[9,35,36]$.

Table 1 details the measures used to assess discrimination, the majority of which measured discrimination in the weeks and months prior to the study, with only a minority measuring lifetime discrimination.

\section{Quality assessment}

The studies which were quality assessed using the EPHPP varied in terms of study quality (see Table 2). 10 out of 24 studies were rated weak in terms of selection bias, most were rated moderate/strong (14 out of 24) as large epidemiological datasets were used, reducing the likelihood of sample bias. In terms of study design, most were rated weak given the cross-sectional nature of identified studies. More than half of the studies were rated moderate/strong (13 out of $24)$ in terms of controlling for confounding variables, and all were rated moderate in terms of outcome assessor and participant blinding, and most were rated as strong/moderate in terms of data collection. However, per EPHPP guidance, if the outcome measures demonstrated face validity, the data collection component could be rated as moderate/ strong (most perceived discrimination measures were unable to demonstrate robust validity).

\section{Do people experiencing psychosis report more discrimination?}

Only two clinical case-control studies tested whether racial discrimination was more prevalent among service users with psychosis than healthy controls; both studies found cases reported more discrimination (see Table 3). However, after controlling for various confounding variables (e.g., ethnicity, employment, education, etc.), no statistically significant relationships were found $[9,37]$. In case-control studies with high-risk individuals [43, 52, 53], results indicated that perceived discrimination was significantly more common in people reporting prodromal psychotic experiences than controls. Regarding non-clinical studies [38, 42, 47, 49, 50, 55, 56], most found positive associations between discrimination and experiences 


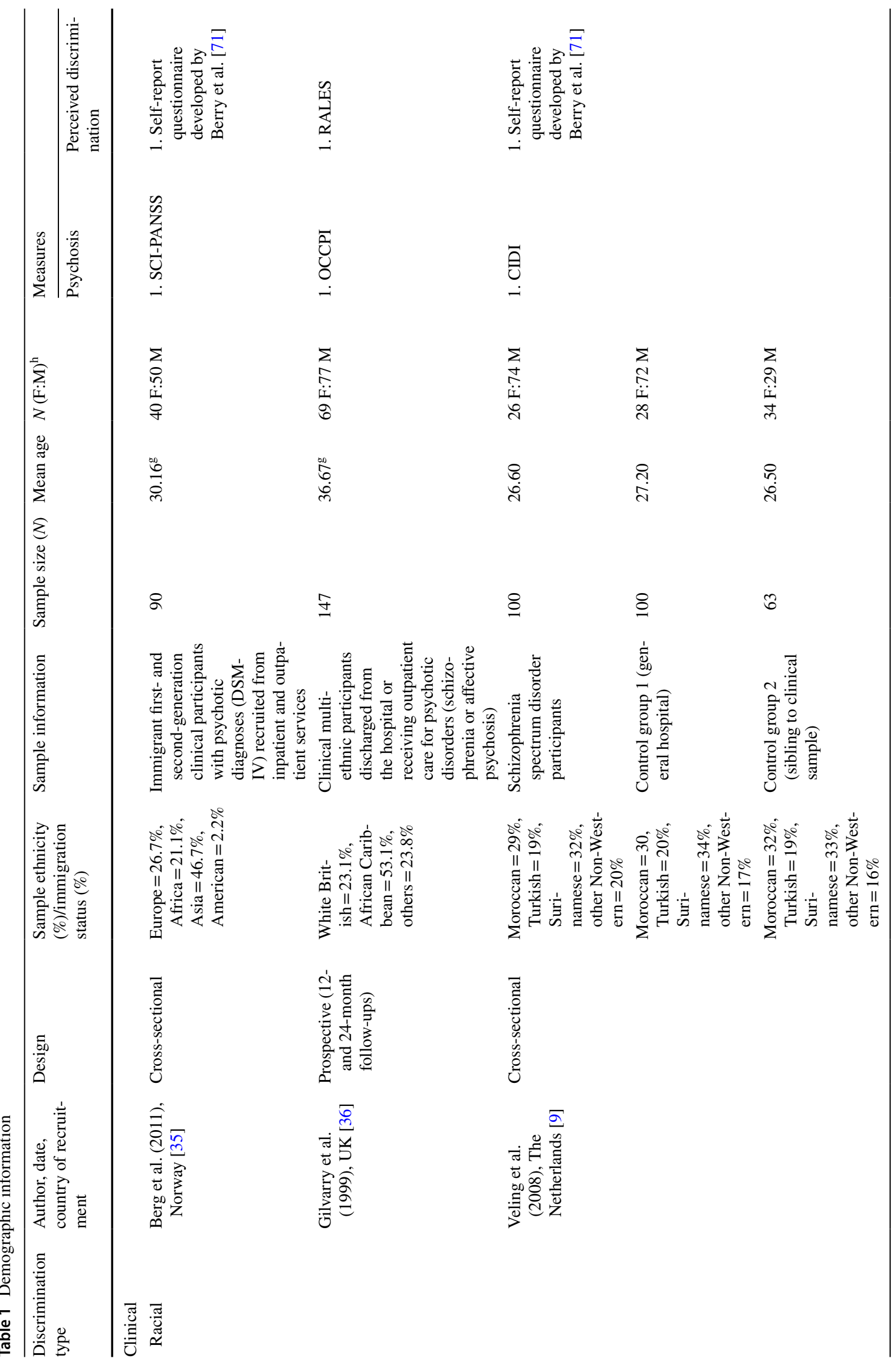




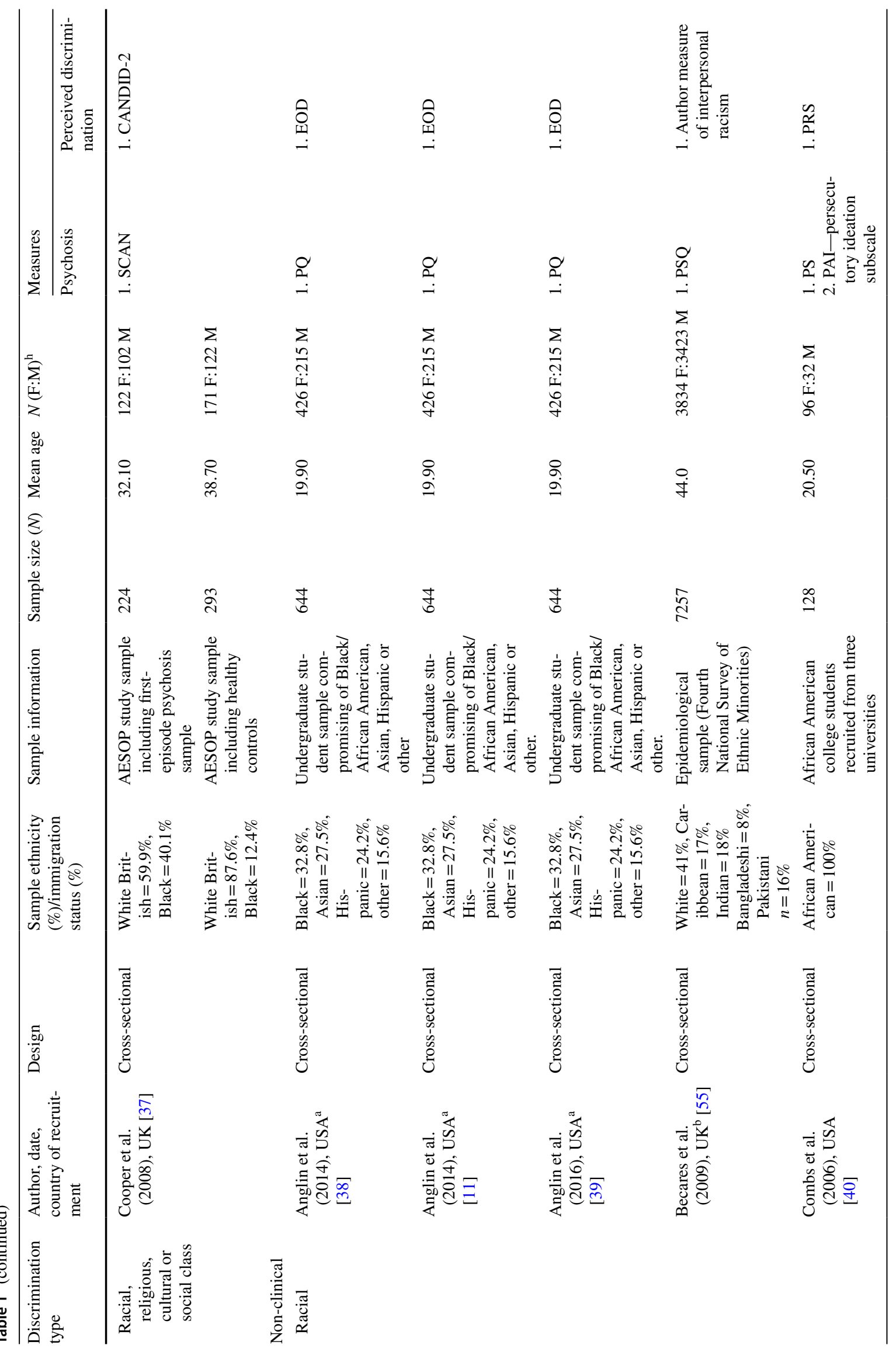




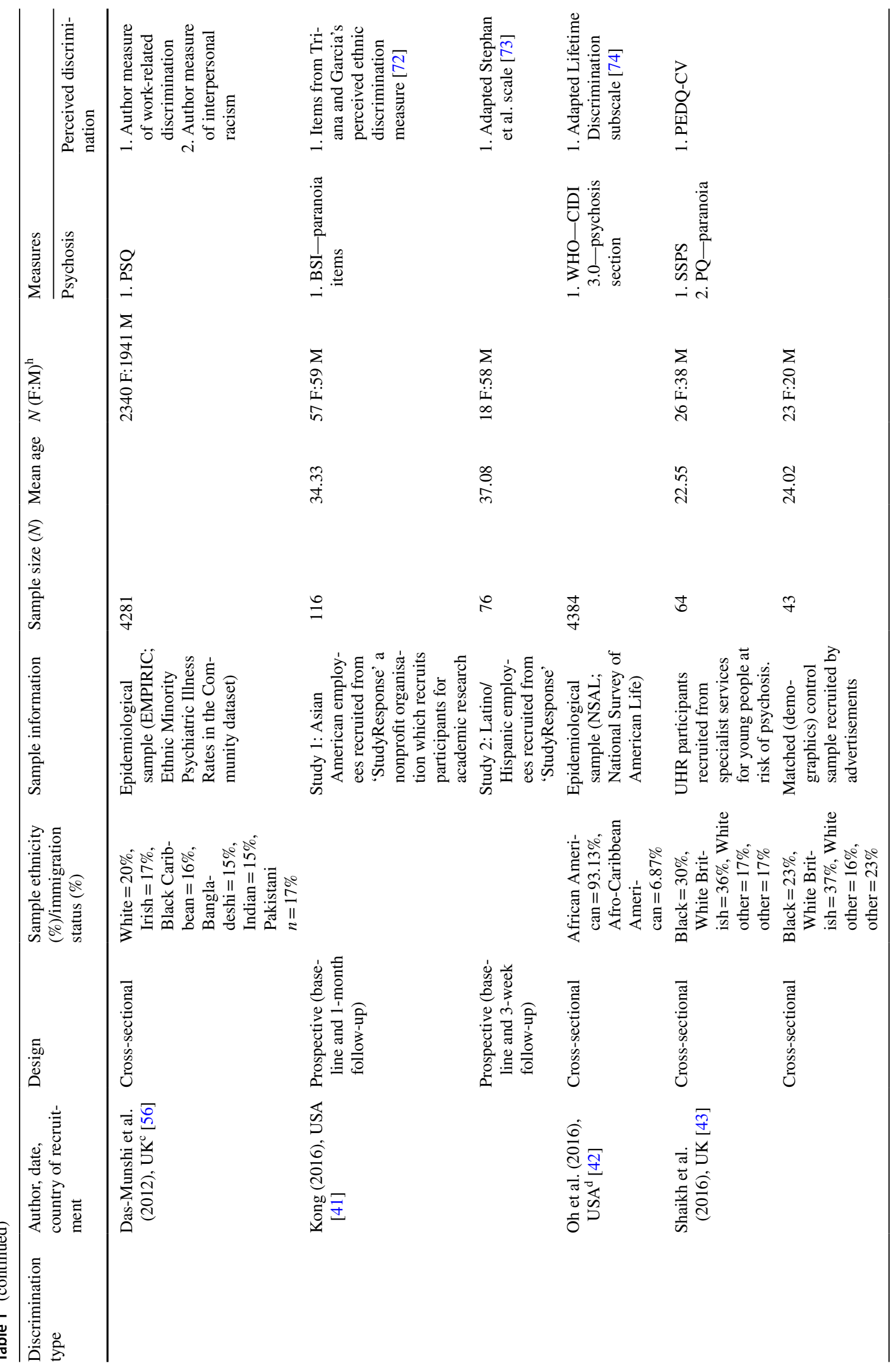




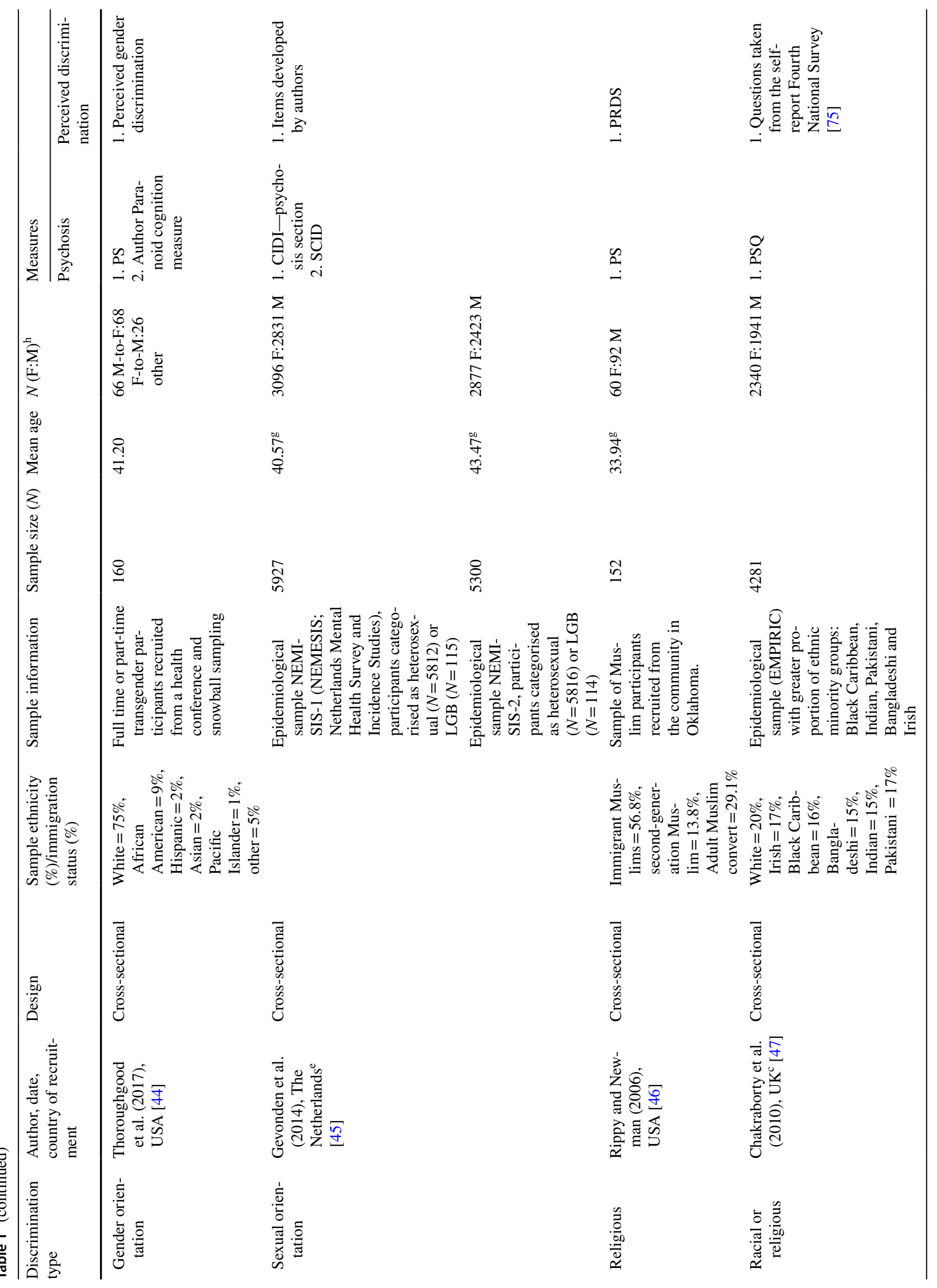




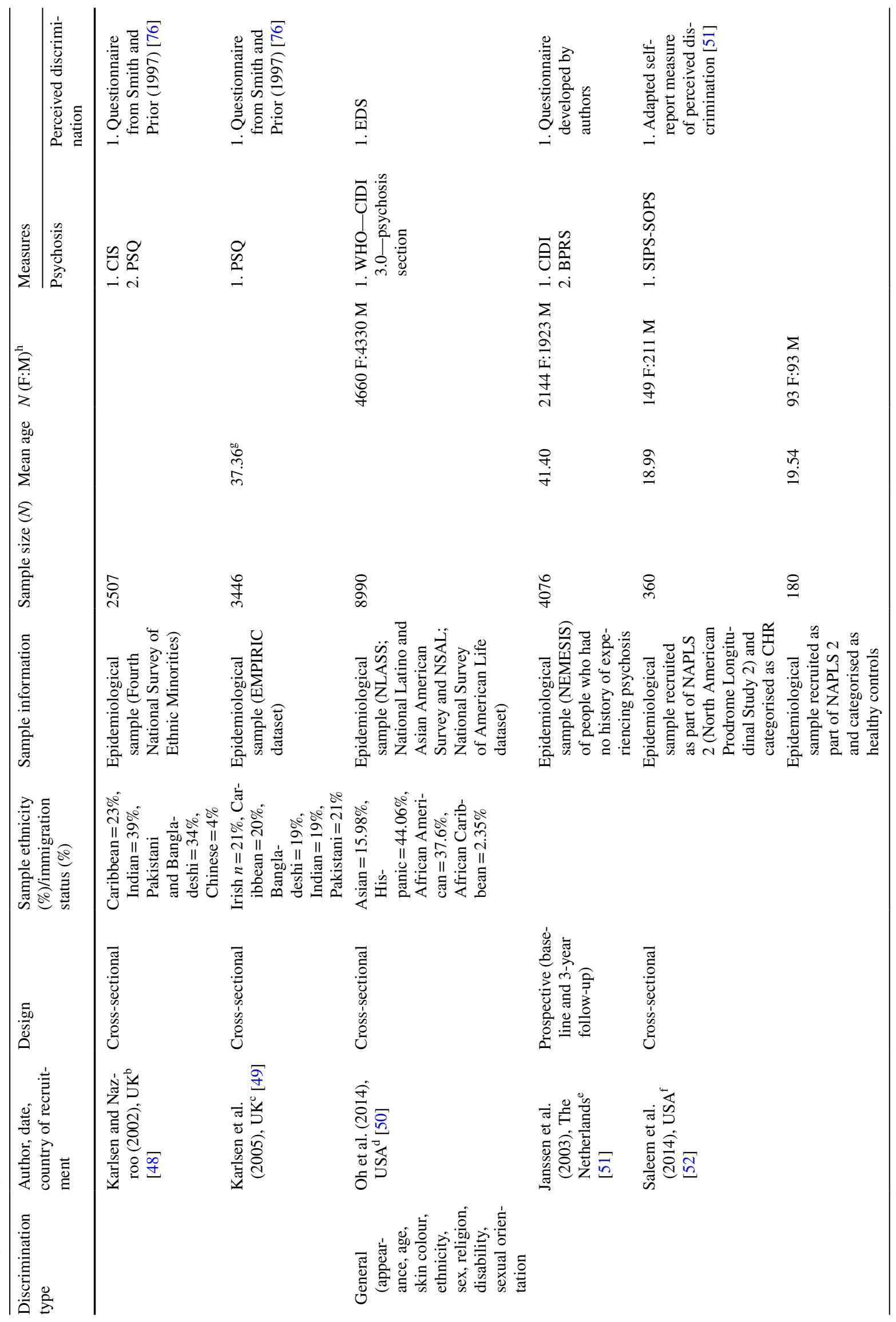




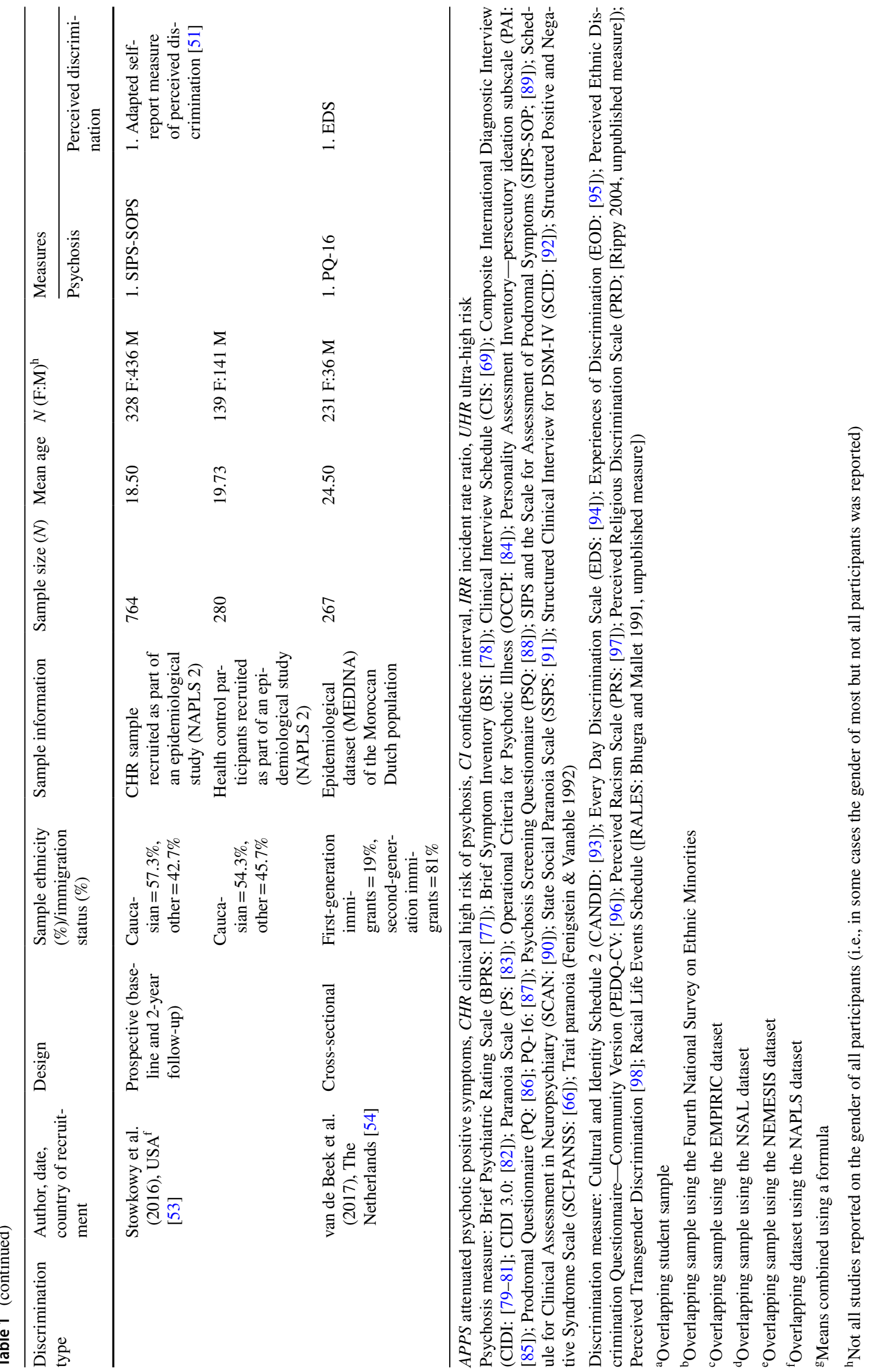


Table 2 Quality appraisal

\begin{tabular}{|c|c|c|c|c|c|c|}
\hline Name of study & Selection bias & Study design & Confounders & Blinding & Data collection & $\begin{array}{l}\text { Withdrawals } \\
\text { and dropouts }\end{array}$ \\
\hline Anglin et al. [38] & Weak & Weak & Moderate & Moderate & Strong & NA \\
\hline Anglin et al. [11] & Weak & Weak & Weak & Moderate & Strong & NA \\
\hline Anglin et al. [39] & Weak & Weak & Weak & Moderate & Strong & NA \\
\hline Becares et al. [55] & Moderate & Weak & Strong & Moderate & Moderate & NA \\
\hline Berg et al. [35] & Moderate & Weak & Weak & Moderate & Strong & NA \\
\hline Chakraborty et al. [47] & Moderate & Weak & Strong & Moderate & Moderate & NA \\
\hline Combs et al. [40] & Weak & Weak & Weak & Moderate & Strong & NA \\
\hline Cooper et al. [37] & Moderate & Moderate & Moderate & Moderate & Strong & NA \\
\hline Das-Munshi et al. [56] & Moderate & Weak & Strong & Moderate & Moderate & NA \\
\hline Gevonden et al. [45] & Moderate & Weak & Strong & Moderate & Moderate & NA \\
\hline Gilvarry et al. [36] & Weak & Moderate & Weak & Moderate & Moderate & Strong \\
\hline Janssen et al. [51] & Strong & Moderate & Strong & Moderate & Moderate & Moderate \\
\hline Karlsen and Nazroo [48] & Moderate & Weak & Weak & Moderate & Moderate & NA \\
\hline Karlsen et al. [49] & Moderate & Weak & Moderate & Moderate & Moderate & NA \\
\hline Kong [41] & Weak & Moderate & Weak & Moderate & Strong & Strong \\
\hline Oh et al. [50] & Strong & Weak & Strong & Moderate & Strong & NA \\
\hline Oh et al. [42] & Moderate & Weak & Strong & Moderate & Strong & NA \\
\hline Rippy and Newman [46] & Weak & Weak & Weak & Moderate & Strong & NA \\
\hline Shaikh et al. [43] & Weak & Weak & Moderate & Moderate & Strong & NA \\
\hline Saleem et al. [52] & Moderate & Moderate & Weak & Moderate & Moderate & NA \\
\hline Stowkowy et al. [53] & Moderate & Moderate & Weak & Moderate & Moderate & Weak \\
\hline Thoroughgood et al. [44] & Weak & Weak & Weak & Moderate & Strong & NA \\
\hline van de Beek et al. [54] & Weak & Weak & Strong & Moderate & Strong & NA \\
\hline Veling et al. [9] & Moderate & Moderate & Strong & Moderate & Strong & NA \\
\hline
\end{tabular}

NA not applicable given the cross-sectional nature of studies

related to psychosis. Interestingly, findings from Karlsen and Nazroo [48] suggested more severe forms of discrimination may be particularly prevalent in people with psychotic experiences, as individuals reporting verbal racial abuse were two times more likely to report psychosis experiences (OR 2.86). The association was seemingly larger for physical racial abuse (OR 4.77) [48].

\section{Is there a relationship between discrimination and severity of psychotic experiences?}

One clinical study found evidence that discrimination was associated with significantly greater severity of psychotic experiences [35], while several non-clinical [38, 40, 44, 46, 54] and one at-risk study [43] found perceived discrimination to be associated with greater frequency of prodromal/ psychotic-like symptoms (severity not investigated). In addition, Anglin et al. [38] reported that people perceiving discrimination were 1.29 times more likely to experience distress as a result of non-clinical psychotic experiences.

\section{Is there a relationship between discrimination and specific experiences within psychosis?}

Seven non-clinical $[38,40,41,44,46,50,51]$, three atrisk studies [43, 52, 53], and two clinical studies [35, 37] examined whether discrimination was associated with a range of specific psychotic experiences. Of the two clinical studies that examined this relationship, one [37] found no specific relationship, while Berg et al. [35] found a positive association between racial discrimination and 'positive psychotic symptoms' (not with 'negative symptoms' or 'cognitive disorganisation'). Of the at-risk studies, two used the same epidemiological dataset [52, 53]; Stowkowy et al. [53] found weak associations between discrimination and specific 'positive psychotic symptoms' and Saleem et al. [52] found no association (Saleem et al., used a smaller dataset). The third study found a relationship between discrimination and paranoia [43]. Similarly, non-clinical studies found discrimination to be associated with paranoia [40, 41, 44], with males reporting higher levels of paranoia than women [40, 46]. In other non-clinical studies, racial discrimination was significantly associated with an increase in all non-clinical 
Table 3 Results

Discrimination type $\quad \begin{aligned} & \text { Author, date, country of Results } \\ & \text { recruitment }\end{aligned}$

recruitment

\section{Clinical}

Racial

Berg et al. (2011), Norway [35]

Gilvarry et al. (1999), UK [36]

Veling et al. (2008), The Netherlands [9]

Racial, religious, cultural or social class

Cooper et al. (2008), UK [37]

Non-clinical

Racial

Anglin et al. (2014), USA ${ }^{\mathrm{a}}$ [38]
Positive correlations were found between perceived discrimination and positive psychotic symptoms $(r=0.26, p<0.050)$. No associations were found between perceived discrimination and negative psychotic symptoms

African Americans reported the most severe 'positive symptoms' and higher rates of perceived discrimination $(t=2.472, d f=88, p<0.015)$. Multiple linear regression demonstrated that the relationship between African immigrant status and severity of symptoms reduced when perceived discrimination was added into the model (Model 1 without covariate: $B=3.096$, SE 1.103, $p=0.006$; Model 2 controlling for perceived discrimination: $B=2.535$, SE $1.123, p=0.270$ ), indicating that it partially mediated the relationship

Logistic regression indicated that Black and ethnic minority individuals were more likely to report life events (financial, health, assault) as being related to discrimination than White British individuals (but not housing life events)

Perceptions of racial discrimination were not associated with diagnosis (schizophrenia vs affective psychosis) or course of illness (episodic vs continuous)

Cases reported slightly higher levels of perceived discrimination (52\%) than both control groups (42\%), but the relationship was not statistically significant. However, cases significantly reported more personal experiences of discrimination than group 1 controls [OR 1.08, 95\% CI (1.01, 1.17)]. However, after controlling for employment, education, marital status, cultural distance, mastery, ethnic identity, self-esteem, social support and cannabis use, no statistically significant differences in perceived discrimination was found between cases and group 1 controls. Additionally, perceived discrimination was reported more by males than females $\left(50 \%\right.$ vs $37 \%, x^{2}=3.38$, $d f=1, p=0.046)$ in the total sample

People experiencing psychosis were more likely to experience racial perceived disadvantage [OR 1.2, 95\% CI $(1.1,1.4)], p<0.009)$ than the control group. However, when higher perceived disadvantage scores by Black people were controlled for, people experiencing psychosis were less likely to attribute disadvantage to skin colour [OR $0.82,95 \%$ CI $(0.68,0.98), p<0.027$ ]. Additionally, greater perceptions of disadvantage were not significantly associated with persecutory delusions, delusions of reference or hallucinations

Psychosis cases were more likely to be from Black ethnic group, and were also more likely to believe they were at a greater disadvantage compared to White people [OR $1.3,95 \%$ CI $(1.1,1.5), p<0.001]$. Additionally, Black ethnic groups were four times more likely to experience psychosis [OR 4.7, 95\% CI $(3.1,7.2), p<0.001$ ] than White people, after controlling for age and gender. This association reduced when perceived disadvantage was added in to the model, indicating that it partially mediated the relationship [OR 4.1, 95\% CI $(2.5,6.8), p<0.001$ ] between case status (controls or psychosis) and Black ethnicity

Positive correlations were found between number of racial discrimination domains (getting housing, credit or medical care, at work, getting hired, in police or courts, getting a service, at school and on the street or in public) and 'attenuated psychotic symptoms' (APPS) $(r=.242, p<.001)$, as well as, the frequency of discrimination and APPS $(r=.249, p<.001)$. Discrimination domains were significantly $(p<.001)$ associated with an increased risk of all psychotic domains: cognitive disorganisation $(r=.229)$, unusual thinking $(r=.197)$, perceptual abnormalities $(r=.199)$ and paranoia $(r=.204)$. Additionally, discrimination frequency was significantly $(p<$ $.001)$ associated with an increased risk of all psychotic domains: cognitive disorganisation $(r=.234)$, unusual thinking $(r=.204)$, perceptual abnormalities $(r=.196)$ and paranoia $(r=.210)$

Racial discrimination was associated with an increased risk of being in the high than low APPS-distress category OR $=1.41$ (95\% CI [1.23, 1.60]). The association remained when race/ethnicity, gender, age and income had been adjusted for OR = 1.29 (95\% CI $[1.10,1.51])$. Therefore, racial discrimination was found to increase the risk of higher levels of distress associated with psychosis 
Table 3 (continued)

Discrimination type $\quad \begin{aligned} & \text { Author, date, country of } \\ & \text { recruitment }\end{aligned}$

Anglin et al. (2016), USA ${ }^{\mathrm{a}}$ Black people were significantly more likely to report racial discrimination compared to 'other' racial groups $(p<.001)$, but not significantly more likely than Asian and Hispanic ethnic/racial groups. Also, there were no racial differences in the number of APPS-distress endorsed

Racial discrimination was associated with APPS-distress and remained significant after adjusting for age $(\beta=.105, p<.001)$. Bootstrapping analyses suggested that the relationship between racial discrimination and APPS-distress was partially mediated by RS-scores (Rejection Sensitivity Questionnaire-Race; participants concerns and expectations of rejection based on their race)

Anglin et al. (2016), USA ${ }^{\mathrm{a}}$ [39]

Becares et al. (2009), UK [55]

Combs et al. (2006), USA [40]

Das-Munshi et al. (2012), $\mathrm{UK}^{\mathrm{c}}[56]$

Kong (2016), USA [41]
At least $70 \%$ of the student sample experienced one type of perceived discrimination, and a positive significant relationship between perceived discrimination and positive psychotic symptoms $(r=0.211, p<0.001)$

Additionally, the relationship between discrimination and positive psychotic symptoms differed based on participant's commitment and exploration of their ethnicity, i.e., ethnic identity (e.g., low ethnic identity, moderate ethnic identity and high ethnic identity). For example, the effect of perceived racial discrimination on positive psychotic symptoms was higher for participants with low ethnic identity $[F(4$, 165 ) $=19.71, p<0.001, R^{2}=0.30$, adjusted $\left.\beta=0.76\right]$ than higher (moderate and high ethnic identity combined) ethnic identity participants $[F(4,457)=51.14, p<0.001$, $R^{2}=0.30$, adjusted $\beta=0.23$ ]

Racial abuse was associated with an increased likelihood of reporting psychotic experiences in the combined ethnic minority group (adjusted OR 3.13, $p<0.001$ ), with Indians (adjusted OR 4.15, $p<0.001$ ) and Caribbean people (adjusted OR 3.47, $p<0.001$ ) demonstrating the strongest likelihood of psychotic experiences

An interaction was found between racial abuse and ethnic density on psychotic symptoms (not significant), with the association between racism and psychotic experiences smaller in areas of high ethnic density

Perceived discrimination was associated with non-clinical $(r=0.40, p<0.001)$ and clinical $(r=0.24, p=0.008)$ levels of paranoia. Males had higher levels of clinical paranoia $(t=2.7, d f=124, p=0.007)$

Multiple regression model was overall significant $\left(R=0.69\right.$, Adj $R^{2}=0.38, F(15$, $81)=5.0, p<0.001)$ showing that perceived discrimination was a significant predictor of non-clinical paranoia, but not a significant predictor of clinical paranoia

In the combined ethnic minority sample (after adjusting for confounding variables), interpersonal racism [OR 2.26, 95\% CI $(1.62,3.14), p<0.001]$ and work-related discrimination [OR $1.46,95 \% \mathrm{CI}(1.06,2.00), p=0.020$ ] were associated with psychotic experiences

When own-group density decreased by $10 \%$, individuals were more likely to report psychotic experiences in all ethnic groups (except for White British). This relationship achieved significance only in the combined (OR 1.03, $p=0.030)$ and Indian (OR 1.38, $p=0.030$ ) samples (not Black Caribbean, Irish, Bangladeshi, and Pakistani samples). Additionally, ethnic minority groups were more likely to report discriminatory experiences and less social support when living in areas of low own-group density

Study 1: Path analysis found that perceived ethnic discrimination was significantly related to paranoia $[\beta=0.48, p<0.001$, bootstrap $95 \% \mathrm{CI}(0.33,0.61)]$

Study 2: Similar to study 1, path analysis found that perceived ethnic discrimination was significantly related to paranoia $[\beta=0.21, p<0.05$, bootstrap $95 \% \mathrm{CI}(0.04$, 0.39)]. Additionally, collective self-esteem was found to moderate the relationship between perceived ethnic discrimination and paranoia, because when collective selfesteem was low, discrimination was positively related to paranoia $(\beta=0.10$, SE 0.03 , $t=2.99, p<0.01)$. However, when collective self-esteem was high, the relationship was not significant $(\beta=-0.06$, SE $0.05, t=-1.14, p=0.26)$ 
Table 3 (continued)

\begin{tabular}{ll}
\hline Discrimination type & $\begin{array}{l}\text { Author, date, country of } \\
\text { recruitment }\end{array}$ \\
\hline
\end{tabular}
recruitment

Oh et al. (2016), USA ${ }^{\mathrm{d}}$ [42] Logistic regression demonstrated that police abuse [adjusted OR 1.69, 95\% CI (1.20, $2.39), p<0.01$ ], being denied a promotion (adjusted [OR 1.44, 95\% CI $(1.07,1.95)$, $p<0.05$ ] or a loan [adjusted OR 1.93, 95\% $(1.16,3.26), p<0.05$ ] was associated with increased lifetime psychotic experiences (these discriminatory experiences were attributed to race, skin colour or ancestry). Also, those who reported one or two discriminatory experiences were $63 \%$ more likely to report psychotic experiences (compared to those reporting none), and those who reported three or more, were twice as likely

Additionally, after controlling for confounders, being denied a promotion (adjusted OR $1.53, p<0.01$ ) or a loan (OR 2.02, $p<0.05$ ), police abuse (adjusted OR 1.82, $p<0.01$ ), and being discouraged from education (adjusted OR 2.02, $p<0.01$ ) was associated with an increased risk of visual hallucinations. Whilst, not being hired (adjusted OR 2.60, $p<0.05$ ), or excluded from the neighbourhood (adjusted OR 2.81, $p<0.05$ ), or discouraged from education (adjusted OR 2.99, $p<0.01$ ), was associated with an increased risk of delusional ideation. No discriminatory experience was associated with auditory hallucinations

Shaikh et al. (2016), UK Perceived ethnic discrimination was significantly higher in the UHR group compared to [43] health controls, $t=3.63, p<0.001$

Positive correlation between perceived ethnic discrimination and persecutory paranoia in virtual reality for the whole sample $(r=0.25, p=0.009)$, but not in individuals at UHR risk $(r=0.119, p=0.360)$, or healthy controls $(r=0.212, p=0.180)$. Logistic regression found that perceived discrimination was not a significant predictor of paranoid ideation in virtual reality for the whole sample $(p=0.25)$ or the UHR group $(p=0.95)$. However, it was a significant predictor in healthy controls (OR 0.046, $p=0.049)$

Positive correlations between perceived discrimination and prodromal psychotic symptoms in the whole sample $(r=0.42, p<0.001)$ and UHR group $(r=0.33, p=0.009)$ no significant correlation in healthy controls $(r=0.09, p=0.560)$

Gender orientation

Sexual orientation

Religious

Racial or religious
Thoroughgood et al. (2017), USA [44]

Gevonden et al. (2014), The Netherlands ${ }^{\mathrm{e}}$ [45]

Rippy and Newman (2006),

Chakraborty et al. (2010), $\mathrm{UK}^{\mathrm{c}}$ [47] USA [46]

Perceived transgender discrimination was significantly associated with trait paranoia $(r=0.40, p<0.01)$ and paranoid cognition at work $(r=0.61, p<0.001)$. After controlling for trait paranoia and negative affect, perceived discrimination was related to paranoid cognition at work $(\beta=0.45, p<0.001)$

Psychosis incidence was significantly elevated in the LGB group compared to the heterosexual group [NEMESIS-1: adjusted OR 2.56, 95\% CI (1.71, 3.84); NEMESIS-2: adjusted OR $2.30,95 \%$ CI $(1.42,3.71)]$. Discrimination in the past year mediated $34 \%$ of the total effect of sexual minority status (e.g., homosexual behaviour) on occurrence of psychotic symptoms $(\mathrm{z}=3.52, p<0.001)$ in NEMESIS-1

Between group analysis demonstrated there were significant differences $(p<0.020)$ between the immigrant, second-generation immigrant, or convert Muslims living in the US in level of perceived discrimination, with second-generation Muslims reporting greater amounts of perceived discrimination than convert $(p<0.050)$ and immigrant Muslims

A positive correlation was found between perceived discrimination and non-clinical paranoia in male but not female Muslims $(r=0.42, p<0.010)$

Racial verbal insults were associated with being categorised as experiencing psychosis (PSQ positive) in Black Caribbean [OR 3.35, 95\% CI $(1.79,6.26)]$, Bangladeshi [OR 5.46, 95\% CI $(1.79,6.26)]$ and Pakistani groups [OR 2.65, 95\% CI $(1.26,5.55)]$. Also, job refusal was associated with being PSQ positive in the Pakistani origin group [OR $2.26,95 \%$ CI $(1.08,4.75)]$. There were no significant associations found between racial discrimination and psychosis in the Indian origin group. (All odds ratios were adjusted for age, gender, social class, number of close persons, and distance of closest person)

Karlsen and Nazroo (2002), Logistic regression analysis revealed that the perception of racial discrimination $\mathrm{UK}^{\mathrm{b}}[48] \quad$ increased the risk of psychosis [OR 1.57, 95\% CI $(1.02,2.42)$ ]

Experiencing verbal racial abuse [OR 2.86, 95\% CI $(1.69,4.83)]$ and physical racial attacks [OR 4.77, 95\% CI $(2.32,9.80)]$ were significantly associated with experiencing psychosis 
Table 3 (continued)

Discrimination type $\quad \begin{aligned} & \text { Author, date, country of } \\ & \text { recruitment }\end{aligned}$

Karlsen et al. (2005), UK ${ }^{\mathrm{c}}$

[49]

General (appearance, age, skin colour, ethnicity, sex, religion, disability, sexual orientation
In the combined sample risk of psychosis was associated with experienced racial verbal abuse [OR 2.18, 95\% CI $(1.31,3.63)]$, and physical racial attack [OR 2.94, 95\% CI $(1.14,7.57)]$, similar results were found for males and females. The Bangladeshi group showed the greatest risk [OR $7.83,95 \% \mathrm{CI}(2.00,30.61)]$ followed by Caribbean [OR 3.45, 95\% CI $(1.73,6.90)$ ] and Pakistani participants [OR 3.36, 95\% (1.58, 7.18)]

Perceived work-related discrimination (attributed to race, religion or ethnic background) was not significantly related to an increased risk of psychosis in the combined sample. However, Caribbean people who perceived employers to be racist had an increased risk of psychosis [OR 2.34, 95\% CI $(1.28,4.28)]$

Oh et al. (2014), USA ${ }^{\mathrm{d}}$ [50] Discriminatory experiences were mostly attributed to race $(64.87 \%$, SE 1.9), followed by other reasons $(23.1 \%$, SE 0.97$)$, height or weight $(2.35 \%$, SE 0.20$)$, gender $(3.7 \%$, SE 0.29$)$ and age $(5.99 \%$, SE 0.57)

Participants experiencing psychosis were more likely to be African American and less likely to be Asian

Multiple logistic regression models demonstrated that participants who reported the highest levels of perceived discrimination (compared to those who experienced no discrimination) were more likely to report experiences of psychosis (moderate levels OR 2.432, high levels OR 3.262). Lower levels of perceived discrimination did not significantly predict psychosis (low levels OR 1.497 and mild levels OR 1.24). The overall likelihood of psychotic experiences increased with greater exposure to discrimination $(\mathrm{z}=12.22, p<0.001)$ indicating a dose-response relationship

Also, higher levels of perceived discrimination were associated with an increased risk of delusions OR 4.278, auditory hallucinations OR 3.843, and visual hallucinations OR 2.971 after controlling for covariates (e.g., age, gender, income, education, immigration status, race, substance abuse, PTSD, region, social interaction and complex survey design)

Janssen et al. (2003), The Netherlands ${ }^{\mathrm{e}}[51]$

Rates of baseline perceived discrimination were: ethnicity/skin colour $(n=75,2 \%)$, age $(n=261,6 \%)$, disability $(n=77,2 \%)$, gender $(n=182,4 \%)$, appearance $(n=80,2 \%)$, and sexual orientation $(n=13,0.3 \%)$

Perceived discrimination predicted the onset of delusional ideation in a dose-response fashion [OR 2.1, 95\% CI $(1.2,3.8), p=0.027$ ], as rate of delusion ideation was $0.5 \%$ in participants reporting one discriminatory, and $2.7 \%$ in those who reported more than one domain. The relationship remained significant after controlling for confounding variables [OR 2.3, 95\% CI 95\% $(1.2,4.2)]$. No association was found between baseline discrimination and hallucinations

Saleem et al. (2014), USA $^{\mathrm{f}}$ [52]

CHR participants had significantly higher frequencies of total perceived discrimination $(z=-6.04, p<0.001)$ and individual experiences (perceived discrimination based on appearance, age, skin colour, religion, disability, sexual orientation, and other, not ethnicity or gender) than the healthy comparison group

CHR had higher levels of negative schemas about self $(U=196.23, p<0.0001)$, and about others $(U=136.04, p<0.0001)$ than the comparison group

Perceived discrimination was not associated with total 'positive symptoms' and specific experiences (unusual thoughts, suspiciousness, grandiose ideas, perceptual abnormalities, disorganised communication) in either the CHR or the comparison group

Perceived discrimination was significantly associated with negative schemas

Stowkowy et al. (2016), $\mathrm{USA}^{\mathrm{f}}[53]$
Perceived discrimination was significantly associated with being in an ethnic minority group in both CHR $(r=-0.15, p<0.0001)$ and healthy control groups $(r=-0.21$, $p<0.01)$. However, CHR participants reported more perceived discrimination compared to controls $(z=-6.44, p<0.0001)$

In the CHR group, perceived discrimination was positively associated with the following psychotic symptoms: grandiose ideas $(r=0.09, p<0.05)$, disorganized communication $(r=0.15, p<0.003$ after Bonferroni correction), and suspiciousness ( $r=0.16$, $p<0.003$ after Bonferroni correction)

Additionally, individuals at a clinical high risk of psychosis who reported significantly more perceived discrimination were more likely to experience later conversion to psychosis, compared to CHR individuals who reported less perceived discrimination. For example, for one discrimination experience endorsed, an individual had a 52.4\% chance of conversion to psychosis [HR 1.101, 95\% CI $(1.002,1.209), p=0.0449]$ 
Table 3 (continued)

\begin{tabular}{|c|c|c|}
\hline Discrimination type & $\begin{array}{l}\text { Author, date, country of } \\
\text { recruitment }\end{array}$ & Results \\
\hline & $\begin{array}{l}\text { van de Beek et al. (2017), } \\
\text { The Netherlands [54] }\end{array}$ & $\begin{array}{l}\text { Regression analyses found that perceived discrimination was associated with greater } \\
\text { psychotic experiences }(\beta=0.257, p<0.001) \text {, the relationship remained significant } \\
\text { after adjusting for age, gender, education, immigration status and social support } \\
(\beta=0.197, p<0.01) \text {, and the regression models explained variance increased after } \\
\text { adjusting for the above-mentioned variables (adjusted } R^{2}=0.179 \text { vs unadjusted } \\
R^{2}=0.062 \text { ) }\end{array}$ \\
\hline
\end{tabular}

\footnotetext{
${ }^{\mathrm{a} O v e r l a p p i n g ~ s t u d e n t ~ s a m p l e ~}$

${ }^{\mathrm{b}}$ Overlapping sample using the Fourth National Survey on Ethnic Minorities

${ }^{\mathrm{c}}$ Overlapping sample using the EMPIRIC dataset

${ }^{\mathrm{d}}$ Overlapping sample using the NSAL dataset

${ }^{\mathrm{e}}$ Overlapping sample using the NEMESIS dataset

${ }^{\mathrm{f}}$ Overlapping dataset using the NAPLS dataset
}

psychotic experiences under scrutiny (i.e., cognitive disorganisation, unusual thinking, altered perceptions and paranoia [38]). When confounding variables were considered, one epidemiological study found racial discrimination to be associated with an increased risk of hallucinations (auditory and visual) and delusions [50]. Another epidemiology study [51] found no association with hallucinations, and instead found a relationship between discrimination and delusional ideation.

\section{Can we regard discrimination as a risk factor for psychosis?}

Evidence for discrimination as a risk factor for psychosis is limited due to the methodological designs of the primary studies. However, two epidemiological datasets showed evidence of a 'dose-response' relationship demonstrating that an increase in exposure to discriminatory experiences (based on sexual orientation, age, gender, disability, skin colour, ethnicity) increased the risk of psychosis in a graded, cumulative fashion $[42,50,51]$. Stowkowy et al. [53] also found that individuals at risk of psychosis who reported greater discrimination were more likely to experience later conversion to psychosis, compared to individuals reporting less discrimination. Additionally, three studies (two clinical and one non-clinical) provided evidence that discrimination mediated the relationship between minority group status (racial and sexual orientation) and psychosis in cross-sectional analyses [35, 37, 45]. However, the strongest evidence for discrimination as a putative risk factor of psychosis was provided by a 3-year prospective study that recruited people with no experience of psychosis at baseline [51]. The authors found that discrimination at baseline predicted the onset of delusional ideation (but not hallucinations) at follow-up in a dose-response fashion. For example, the rate of delusional ideation was $0.5 \%$ for those reporting no discriminatory experience, $0.9 \%$ for those reporting one type of discriminatory experience (e.g., age) and $2.7 \%$ for individuals reporting more than one type of these discriminatory experiences (e.g., age, gender, etc.). Interestingly, one study also found collective self-esteem to moderate the relationship between discrimination and paranoia in a non-clinical sample [41] suggesting a potential avenue for intervention.

\section{Discussion}

This review synthesised existing quantitative studies that examined: (1) whether perceived minority discrimination is more common in people with psychosis relative to controls; (2) whether discrimination is associated with increased severity of psychotic experiences, and (3) whether discrimination is associated with increased vulnerability to and/or severity of specific psychotic experiences. In regard to the first aim, of the two clinical case-control studies identified, neither study found a relationship after confounding variables had been controlled for [9, 37]. However, non-clinical case-control studies found that non-clinical participants reporting psychotic-like experiences reported more discrimination than controls (e.g., [43]). Regarding the second aim, one clinical study [35] found that discrimination was associated with an increase in psychosis severity; the remaining eligible studies which were non-clinical and examined associations between discrimination and the frequency of psychotic experiences rather than severity. Furthermore, several investigations suggest that the relationship between discrimination and psychotic experiences might be more robust for positive symptoms of psychosis, and/or specific psychotic experiences, in particular, paranoid/persecutory beliefs in non-clinical samples (e.g., [40, 41, 44]). 
The studies that examined the association between minority discrimination and psychosis are predominantly crosssectional, therefore precluding the unambiguous determination of the direction of influence and/or causality. A growing number of findings, however, suggest that the impact of discrimination on psychosis liability and severity should not be understated. First, meditational analyses (conducted on cross-sectional data) indicated that perceived discrimination is an important mediator of the relationship between belonging to a minority group and the likelihood of reporting psychotic experiences $[35,37,45]$. Second, prospective evidence indicates that non-psychotic individuals can develop psychotic-like experiences (delusional ideation) [51], and later conversion to psychosis [53] following experiences they perceived as discriminatory. Third, a small number of studies tested whether the association between discrimination and psychosis varied in a dose-response fashion. A graded relationship was observed, with more severe and/or pervasive experiences of discriminations leading to heightened risk of psychotic symptoms [42, 50, 51]. These findings, although sparse, are particularly pertinent to key criteria to gauge whether the observed relationships between the phenomena under scrutiny might be causal (e.g., dose-response relationships and temporality are amongst the Bradford Hill criteria for causation [57]), therefore highlighting the need to investigate the relationship between minority discrimination and psychosis further. However, other variables may account for the possible association between discrimination and psychosis. For example, research evidence suggests that people experiencing psychosis are more vulnerable to a range of adverse life experiences after the onset of symptoms, including stigma [58,59] and violent victimisation [60, 61]. These experiences could then be perceived/appraised as resulting from discrimination in people, belonging to ethnic, sexual or other minorities. Research has demonstrated that people experiencing psychosis often have more negative schema about others, which can lead to biased threat-based attributional styles [28, 62]. These explanations are seemingly in line with research findings suggesting that perceived discrimination is associated with negative schemas regarding the self and others [52].

Research findings suggesting a relationship between minority discrimination and psychosis are concordant with psychological models of psychotic experiences and research evidence linking other social adversities to an increased risk for psychosis. The literature synthesised in this review bears parallels with studies that examined the contribution of social deprivation and inequality to the development of psychosis [14]. Growing evidence indicates that social and income inequality are more strongly associated with an increased risk of psychosis than overall deprivation per se $[24,26,63]$. Therefore, it is possible that the experience of discrimination may lead to increased vulnerability to psychotic experiences (and other mental health difficulties) due to the intrinsic social inequalities that underpin discrimination. Social defeat theory and cognitive models of psychosis also offer potential explanations for this link. According to these accounts, chronic social threat and experiences of subordination could lead to increased risk for psychosis via a number of neurophysiological (e.g., HPA axis dysregulation) and psychological (e.g., development of negative self-other schemas) changes; these proposed pathways to psychosis have already been supported by empirical studies [52, 64]. These accounts not only provide plausible theoretical explanations to understand the apparent associations between discrimination and psychosis, but could also guide future mechanistic research to understand the biological and psychosocial processes that might explain the development of psychotic experiences in people subjected to discrimination. Future carefully designed longitudinal research is required to clarify these findings and determine whether discrimination might represent a contributing factor for psychosis.

Despite the intriguing findings, some studies did not identify statistically significant associations between discrimination and psychosis. One issue is the self-report nature of the discrimination measures included in the review. Researchers suggest that when individuals are asked to disclose their exposure to discrimination, some may have either forgotten or respond in a socially desirable manner in order to avoid scepticism, and therefore may under-report perceived discrimination [64]. There is some evidence to support this notion as Krieger et al. [65] found that individuals who score high on social desirability report less discrimination. Hence, these reporting biases might affect the magnitude and consistency of the associations between perceived discrimination and psychosis considered in the primary studies examined in this review. Additionally, several methodological issues with the primary studies should be considered while appraising the overall findings. There was considerable variation in the way that discrimination was operationalised and measured in the primary studies. For example, certain studies employed lifetime experiences of discrimination [37], while others only considered recent experiences of perceived discrimination [36]. In most cases, the way discrimination was assessed in primary studies precluded to determine with confidence whether psychotic symptoms emerged and/or were aggravated following experiences of discrimination, or whether people who were already psychosis prone might be more disposed to perceiving negative events as discriminatory. To distinguish between these two potential explanations, future studies should employ either longitudinal designs (which have already shown promising results [51]) or more detailed retrospective assessments of both discrimination and the participants' clinical history allowing to determine with greater confidence whether discrimination was experienced prior to or following the onset 
of psychotic experiences. The use of more thorough assessments of discrimination could also clarify certain null findings in the primary studies. For example, the studies that found no association between discrimination and psychosis [52] only considered recent experiences of discrimination (within 12 months), whereas research which considered lifetime discrimination bore more promising findings [35].

Another methodological difficulty intrinsic to this research area is the potential overlap between certain psychotic experiences (in particular paranoid ideation, an experience linked to appraisals of social scrutiny, threat to social status, self-consciousness and hypervigilance [66]) and the justified and ultimately non-pathological concerns about the intentions of others experienced by discriminated groups. The use of psychosis assessment measures that could better disentangle between common psychological consequences of discrimination and "frank" symptoms of psychosis may further clarify the nature of the relationship between discrimination and psychotic experiences. For example, some of the review findings indicated that discrimination was more strongly associated with non-clinical paranoia [40, 46] than clinical paranoia and that discrimination was associated with negative self-other schemas [52]. This might suggest that discrimination may not be necessarily involved in the development of clinical levels of paranoia but rather that it increases mistrust and suspiciousness (non-clinical paranoia), a hypothesis that is supported by previous findings reporting that ethnic minority groups, although scoring higher on non-clinical measures of paranoia, did not report higher levels of clinical paranoia than non-ethnic minority groups [67]. Despite this, studies have demonstrated that minority groups demonstrate higher rates of clinically relevant experiences [6].

In addition to the above, a number of methodological limitations should be considered. This review attempted to synthesise all quantitative empirical studies which examined the association between discrimination and psychosis, and the included studies varied considerably in terms of research designs, participant samples, assessment instruments and research questions. For this reason, we opted to provide a narrative integration of the research evidence rather than employing meta-analytic methods to describe and synthesise this research corpus. Narrative approaches to evidence syntheses are associated with numerous biases [68]; as the volume of empirical research into the impact of discrimination increases, future evidence syntheses may attempt to examine the research questions considered in this review using meta-analysis. Additionally, most of the included studies varied in terms of study quality. The most notable limitation was that eleven out of twenty-four studies did not take into consideration important confounding variables (e.g., adverse experiences, ethnicity). Failing to control for such experiences hinders confidence that the association between discrimination and psychosis was not confounded by other variables known to affect the relationship [11, 37, 69].

\section{Implications for research and clinical practice}

This review bears several implications for future research. Studies aiming to clarify whether minority discrimination is associated with specific psychotic experiences will benefit from more robust methodological designs and the use of multidimensional, validated measures of psychotic experiences and discrimination (including specific experiences, frequency and severity). Additional prospective research, considerations of potential mediating mechanisms (e.g., attributional style, negative self and other schemas) and important covariates (e.g., previous trauma/adversity) may clarify the pathways linking discrimination to increased psychosis risk. The majority of studies included in the review examined the relationship between discrimination and psychosis in samples of people from ethnic minorities and therefore specifically focussed on racial discrimination. Due to this, it is not possible to examine whether the link between discrimination and psychosis is stronger/more prevalent in different minority groups or discrimination types. However, a few clinical studies $[35,37]$ suggest individuals from Black ethnic groups are more likely to experience discrimination (and consequently more likely to experience psychotic experiences). Future research should explore the relationship across a range of minority groups (e.g., people with physical disabilities, sexual orientation and gender minorities), and discrimination types (e.g., age, sex).

The results suggest that discrimination plays an important role in the experience of psychosis and, as such, during the development of clinical formulations it is essential that clinicians consider discrimination, particularly with persons from visible minorities. In addition to individual intervention, interventions informed by community psychology perspectives could show promise. Such interventions aspire to change social relations and social systems through, for example, empowerment, involvement, networking, and promoting equal opportunities for people from minority groups [70] as well as improving ethnic identification and building collective self-esteem [39, 41]. In support, Anglin et al. [39] found tentative support that having a stronger connection to one's ethnic background may reduce the risk for psychotic symptoms. Similarly, Kong [41] found no relationship between perceived discrimination and paranoia in those with high collective self-esteem than low self-esteem. Therefore, an intervention (considering discrimination and other adverse social equalities) involving the promotion of a sharing, supporting and trusting society in which communities experience togetherness, acceptance and solidarity, may represent a promising option for the prevention and 
management of severe psychological difficulties linked to minority discrimination.

\section{Compliance with ethical standards}

Conflict of interest All authors declare that they have no conflict of interest.

Open Access This article is distributed under the terms of the Creative Commons Attribution 4.0 International License (http://creativeco mmons.org/licenses/by/4.0/), which permits unrestricted use, distribution, and reproduction in any medium, provided you give appropriate credit to the original author(s) and the source, provide a link to the Creative Commons license, and indicate if changes were made.

\section{References}

1. Fearon P, Kirkbride JB, Morgan C, Dazzan P, Morgan K, Lloyd T, Hutchinson G, Tarrant J, Fung WL, Holloway J, Mallett R, Harrison G, Leff J, Jones PB, Murray RM, Group AS (2006) Incidence of schizophrenia and other psychoses in ethnic minority groups: results from the MRC AESOP Study. Psychol Med 36:1541-1550. https://doi.org/10.1017/s0033291706008774

2. Cantor-Graae E, Selten JP (2005) Schizophrenia and migration: a meta-analysis and review. Am J Psychiatry 162:12-24. https:// doi.org/10.1176/appi.ajp.162.1.12

3. Bresnahan M, Begg MD, Brown A, Schaefer C, Sohler N, Insel B, Vella L, Susser E (2007) Race and risk of schizophrenia in a US birth cohort: another example of health disparity? Int J Epidemiol 36:751-758. https://doi.org/10.1093/ije/dym041

4. Chakraborty A, McManus S, Brugha TS, Bebbington P, King M (2011) Mental health of the non-heterosexual population of England. Br J Psychiatry 198:143-148. https://doi.org/10.1192/ bjp.bp.110.082271

5. Bourque F, van der Ven E, Malla A (2011) A meta-analysis of the risk for psychotic disorders among first-and second-generation immigrants. Psychol Med 41:897-910. https://doi.org/10.1017/ S0033291710001406

6. Kirkbride JB, Errazuriz A, Croudace TJ, Morgan C, Jackson D, Boydell J, Murray RM, Jones PB (2012) Incidence of schizophrenia and other psychoses in England, 1950-2009: a systematic review and meta-analyses (incidence of psychosis in England). PLoS One 7:e31660. https://doi.org/10.1371/journal.pone.00316 60

7. Tortelli A, Errazuriz A, Croudace T, Morgan C, Murray RM, Jones PB, Szoke A, Kirkbride JB (2015) Schizophrenia and other psychotic disorders in Caribbean-born migrants and their descendants in England: systematic review and meta-analysis of incidence rates, 1950-2013. Soc Psychiatry Psychiatr Epidemiol 50:1039-1055. https://doi.org/10.1007/s00127-015-1021-6

8. Boydell J, van Os J, McKenzie K, Allardyce J, Goel R, McCreadie RG, Murray RM (2001) Incidence of schizophrenia in ethnic minorities in London: ecological study into interactions with environment. Br Med J 323:1336-1338. https://doi. org/10.1136/bmj.323.7325.1336

9. Veling W, Hoek HW, Mackenbach JP (2008) Perceived discrimination and the risk of schizophrenia in ethnic minorities. Soc Psychiatry Psychiatr Epidemiol 43:953-959. https://doi. org/10.1007/s00127-008-0381-6

10. van Os J, Kenis G, Rutten BP (2010) The environment and schizophrenia. Nature 468:203-212. https://doi.org/10.1038/ nature 09563
11. Anglin DM, Greenspoon M, Lighty Q, Ellman LM (2014) Racebased rejection sensitivity partially accounts for the relationship between racial discrimination and distressing attenuated positive psychotic symptoms. Early Interv Psychiatry 10:411-418. https://doi.org/10.1111/eip.12184

12. Varese F, Smeets F, Drukker M, Lieverse R, Lataster T, Viechtbauer W, Read J, van Os J, Bentall RP (2012) Childhood adversities increase the risk of psychosis: a meta-analysis of patient-control, prospective- and cross-sectional cohort studies. Schizophr Bull 38:661-671. https://doi.org/10.1093/schbu $1 / \operatorname{sbs} 050$

13. Beards S, Gayer-Anderson C, Borges S, Dewey ME, Fisher HL, Morgan C (2013) Life events and psychosis: a review and metaanalysis. Schizophr Bull 39:740-747. https://doi.org/10.1093/ schbul/sbt065

14. Wickham S, Taylor P, Shevlin M, Bentall RP (2014) The impact of social deprivation on paranoia, hallucinations, mania and depression: the role of discrimination social support, stress and trust. PLoS One 9:e105140. https://doi.org/10.1371/journal.pone.01051 40

15. Björkqvist K (2001) Social defeat as a stressor in humans. Physiol Behav 73:435-442. https://doi.org/10.1016/S0031-9384(01)00490 $-5$

16. Shah JL, Malla AK (2015) Much ado about much: stress, dynamic biomarkers and HPA axis dysregulation along the trajectory to psychosis. Schizophr Res 162:253-260. https://doi.org/10.1016/j. schres.2015.01.010

17. Selten JP, Cantor-Graae E (2005) Social defeat: risk factor for schizophrenia? Br J Psychiatry 187:101-102. https://doi. org/10.1192/bjp.187.2.101

18. Fryers T, Melzer D, Jenkins R (2003) Social inequalities and the common mental disorders: a systematic review of the evidence. Soc Psychiatry Psychiatr Epidemiol 38:229-237. https://doi. org/10.1007/s00127-003-0627-2

19. Gilman S, Bruce M, Have T, Alexopoulos G, Mulsant B, Reynolds C, Cohen A (2013) Social inequalities in depression and suicidal ideation among older primary care patients. Soc Psychiatry Psychiatr Epidemiol 48:59-69. https://doi.org/10.1007/s0012 7-012-0575-9

20. Kim D, Kawachi I, Hoorn SV, Ezzati M (2008) Is inequality at the heart of it? Cross-country associations of income inequality with cardiovascular diseases and risk factors. Soc Sci Med 66:1719-1732. https://doi.org/10.1016/j.socscimed.2007.12.030

21. Lorant V, Croux $\mathrm{C}$, Weich $\mathrm{S}$, Deliège $\mathrm{D}$, Mackenbach J, Ansseau M (2007) Depression and socio-economic risk factors: 7-year longitudinal population study. Br J Psychiatry 190:293-298. https:// doi.org/10.1192/bjp.bp.105.020040

22. Marmot M, Bell R (2012) Fair society, healthy lives. Public Health 126:S4-S10. https://doi.org/10.1016/j.puhe.2012.05.014

23. Wilkinson RG, Pickett KE (2009) Income inequality and social dysfunction. Annu Rev Sociol 35:493-511. https://doi. org/10.1146/annurev-soc-070308-115926

24. Kirkbride JB, Jones PB, Ullrich S, Coid JW (2014) Social deprivation, inequality, and the neighborhood-level incidence of psychotic syndromes in East London. Schizophr Bull 40:169-180. https://doi.org/10.1093/schbul/sbs151

25. Burns J, Esterhuizen T (2008) Poverty, inequality and the treated incidence of first-episode psychosis. Soc Psychiatry Psychiatr Epidemiol 43:331-335. https://doi.org/10.1007/s00127-008-0308-2

26. Burns JK, Tomita A, Kapadia AS (2014) Income inequality and schizophrenia: increased schizophrenia incidence in countries with high levels of income inequality. Int J Soc Psychiatry 60:185-196. https://doi.org/10.1177/0020764013481426

27. Wickham S, Shryane N, Lyons M, Dickins T, Bentall R (2014) Why does relative deprivation affect mental health? The role of justice, trust and social rank in psychological wellbeing and 
paranoid ideation. J Public Ment Health 13:114-126. https://doi. org/10.1108/JPMH-06-2013-0049

28. Garety PA, Kuipers E, Fowler D, Freeman D, Bebbington PE (2001) A cognitive model of the positive symptoms of psychosis. Psychol Med 31:189-195. https://doi.org/10.1017/S003329170 1003312

29. McKenzie K, van Os J, Fahy T, Jones P, Harvey I, Toone B, Murray R (1995) Psychosis with good prognosis in Afro-Caribbean people now living in the United Kingdom. BMJ 311:1325. https ://doi.org/10.1136/bmj.311.7016.1325

30. Mirowsky J, Ross C (1983) Paranoia and the structure of powerlessness. Am Sociol Rev 48:228-239

31. Moher D, Liberati A, Tetzlaff J, Altman DG, Group P (2009) Preferred reporting items for systematic reviews and meta-analyses: the PRISMA statement. BMJ 339:b2535. https://doi.org/10.1136/ bmj.b2535

32. Thomas BH, Ciliska D, Dobbins M, Micucci S (2004) A Process for systematically reviewing the literature: providing the research evidence for public health nursing interventions. Worldviews Evid Based Nurs 1:176-184. https://doi.org/10.1111/j.1524475X.2004.04006.X

33. Armijo-olivo S, Stiles CR, Hagen NA, Biondo PD, Cummings GG (2012) Assessment of study quality for systematic reviews: a comparison of the Cochrane Collaboration Risk of Bias Tool and the Effective Public Health Practice Project Quality Assessment Tool: methodological research. J Eval Clin Pract 18:12-18. https ://doi.org/10.1111/j.1365-2753.2010.01516.x

34. La Torre G, Chiaradia G, Gianfagna F, Boccia S, De Laurentis A, Ricciardi W (2006) Quality assessment in meta-analysis. Ital J Public Health 3:44-50. https://doi.org/10.2427/5937

35. Berg AO, Melle I, Rossberg JI, Romm KL, Larsson S, Lagerberg TV, Andreassen OA, Hauff E (2011) Perceived discrimination is associated with severity of positive and depression/anxiety symptoms in immigrants with psychosis: a cross-sectional study. BMC Psychiatry. https://doi.org/10.1186/1471-244x-11-77

36. Gilvarry CM, Walsh E, Samele C, Hutchinson G, Mallett R, RabeHesketh S, Fahy T, van Os J, Murray RM (1999) Life events, ethnicity and perceptions of discrimination in patients with severe mental illness. Soc Psychiatry Psychiatr Epidemiol 34:600-608. https://doi.org/10.1007/s001270050181

37. Cooper C, Morgan C, Byrne M, Dazzan P, Morgan K, Hutchinson G, Doody GA, Harrison G, Leff J, Jones P, Ismail K, Murray R, Bebbington PE, Fearon P (2008) Perceptions of disadvantage, ethnicity and psychosis. Br J Psychiatry 192:185-190. https://doi. org/10.1192/bjp.bp.107.042291

38. Anglin DM, Lighty Q, Greenspoon M, Ellman LM (2014) Racial discrimination is associated with distressing subthreshold positive psychotic symptoms among US urban ethnic minority young adults. Soc Psychiatry Psychiatr Epidemiol 49:1545-1555. https ://doi.org/10.1007/s00127-014-0870-8

39. Anglin DM, Lui F, Espinosa A, Tikhonov A, Ellman L (2016) Ethnic identity, racial discrimination and attenuated psychotic symptoms in an urban population of emerging adults. Early Interv Psychiatry 12:380-390. https://doi.org/10.1111/eip.12314

40. Combs DR, Penn DL, Cassisi J, Michael C, Wood T, Wanner J, Adams S (2006) Perceived racism as a predictor of paranoia among African Americans. J Black Psychol 32:87-104. https:// doi.org/10.1177/0095798405283175

41. Kong DT (2016) Ethnic minorities' paranoia and self-preservative work behaviors in response to perceived ethnic discrimination, with collective self-esteem as a buffer. J Occup Health Psychol 21:334-351. https://doi.org/10.1037/ocp0000013

42. Oh H, Cogburn CD, Anglin D, Lukens E, DeVylder J (2016) Major discriminatory events and risk for psychotic experiences among Black Americans. Am J Orthopsychiatry 86:277-285. https://doi.org/10.1037/ort0000158
43. Shaikh M, Ellett L, Dutt A, Day F, Laing J, Kroll J, Petrella S, McGuire P, Valmaggia LR (2016) Perceived ethnic discrimination and persecutory paranoia in individuals at ultra-high risk for psychosis. Psychiatry Res 241:309-314. https://doi.org/10.1016/j. psychres.2016.05.006

44. Thoroughgood CN, Sawyer KB, Webster JR (2017) What lies beneath: how paranoid cognition explains the relations between transgender employees' perceptions of discrimination at work and their job attitudes and wellbeing. J Vocat Behav 103:99-112. https ://doi.org/10.1016/j.jvb.2017.07.009

45. Gevonden MJ, Selten JP, Myin-Germeys I, de Graaf R, ten Have M, van Dorsselaer S, van Os J, Veling W (2014) Sexual minority status and psychotic symptoms: findings from the Netherlands Mental Health Survey and Incidence Studies (NEMESIS). Psychol Med 44:421-433. https://doi.org/10.1017/S0033291713000718

46. Rippy AE, Newman E (2006) Perceived religious discrimination and its relationship to anxiety and paranoia among Muslim Americans. J Muslim Ment Health 1:5-20. https://doi. org/10.1080/15564900600654351

47. Chakraborty AT, McKenzie KJ, Hajat S, Stansfeld SA (2010) Racism, mental illness and social support in the UK. Soc Psychiatry Psychiatr Epidemiol 45:1115-1124. https://doi.org/10.1007/s0012 7-009-0156-8

48. Karlsen S, Nazroo JY (2002) Relation between racial discrimination, social class, and health among ethnic minority groups. Am J Public Health 92:624-631

49. Karlsen S, Nazroo JY, McKenzie K, Bhui K, Weigh S (2005) Racism, psychosis and common mental disorder among ethnic minority groups in England. Psychol Med 35:1795-1803. https ://doi.org/10.1017/S0033291705005830

50. Oh H, Yang LH, Anglin DM, DeVylder JE (2014) Perceived discrimination and psychotic experiences across multiple ethnic groups in the United States. Schizophr Res 157:259-265. https:// doi.org/10.1016/j.schres.2014.04.036

51. Janssen I, Hanssen M, Bak M, Bijl RV, De Graaf R, Vollebergh W, McKenzie K, van Os J (2003) Discrimination and delusional ideation. Br J Psychiatry 182:71-76. https://doi.org/10.1192/ bjp.182.1.71

52. Saleem MM, Stowkowy J, Cadenhead KS, Cannon TD, Cornblatt BA, McGlashan TH, Perkins DO, Seidman LJ, Tsuang MT, Walker EF, Woods SW, Addington J (2014) Perceived discrimination in those at clinical high risk for psychosis. Early Interv Psychiatry 8:77-81. https://doi.org/10.1111/eip.12058

53. Stowkowy J, Liu L, Cadenhead KS, Cannon TD, Cornblatt BA, McGlashan TH, Perkins DO, Seidman LJ, Tsuang MT, Walker EF, Woods SW, Bearden CE, Mathalon DH, Addington J (2016) Early traumatic experiences, perceived discrimination and conversion to psychosis in those at clinical high risk for psychosis. Soc Psychiatry Psychiatr Epidemiol 51:497-503. https://doi.org/10.1007/ s00127-016-1182-y

54. van de Beek MH, van der Krieke L, Schoevers RA, Veling W (2017) Social exclusion and psychopathology in an online cohort of Moroccan-Dutch migrants: results of the MEDINA-study. PLoS One 12:e0179827. https://doi.org/10.1371/journal.pone.0179827

55. Becares L, Nazroo J, Stafford M (2009) The buffering effects of ethnic density on experienced racism and health. Health Place 15:670-678. https://doi.org/10.1016/j.healthplace.2008.10.008

56. Das-Munshi J, Becares L, Boydell JE, Dewey ME, Morgan C, Stansfeld SA, Prince MJ (2012) Ethnic density as a buffer for psychotic experiences: findings from a national survey (EMPIRIC). Br J Psychiatry 201:282-290. https://doi. org/10.1192/bjp.bp.111.102376

57. Hill AB (1965) The environment and disease: association or causation? Proc R Soc Med 58:295-300

58. Gerlinger G, Hauser M, Hert M, Lacluyse K, Wampers M, Correll CU (2013) Personal stigma in schizophrenia spectrum 
disorders: a systematic review of prevalence rates, correlates, impact and interventions. World Psychiatry 12:155-164. https ://doi.org/10.1002/wps.20040

59. Wood L, Burke E, Byrne R, Pyle M, Chapman N, Morrison A (2015) Stigma in psychosis: a thematic synthesis of current qualitative evidence. Psychos 7:152-165. https://doi. org/10.1080/17522439.2014.926561

60. Langeveld J, Bjørkly S, Evensen J, Joa I, Johannessen JO, Larsen TK, Melle I, Opjordsmoen S, Røssberg JI, Rund BR (2018) A 10-year follow-up study of violent victimization in first episode psychosis: risk and protective factors. Psychiatry Res 259:545-549. https://doi.org/10.1016/j.psych res.2017.11.013

61. Khalifeh H, Oram S, Osborn D, Howard LM, Johnson S (2016) Recent physical and sexual violence against adults with severe mental illness: a systematic review and meta-analysis. Int Rev Psychiatry 28:433-451. https://doi.org/10.1080/09540 261.2016.1223608

62. Birchwood M, Meaden A, Trower P, Gilbert P, Plaistow J (2000) The power and omnipotence of voices: subordination and entrapment by voices and significant others. Psychol Med 30:337-344

63. Harrison G, Gunnell D, Glazebrook C, Page K, Kwiecinski R (2001) Association between schizophrenia and social inequality at birth: case-control study. Br J Psychiatry 179:346-350. https ://doi.org/10.1192/bjp.179.4.346

64. Stowkowy J, Addington J (2012) Maladaptive schemas as a mediator between social defeat and positive symptoms in young people at clinical high risk for psychosis. Early Interv Psychiatry 6:87-90. https://doi.org/10.1111/j.1751-7893.2011.00297.x

65. Gee GC, Spencer M, Chen J, Yip T, Takeuchi DT (2007) The association between self-reported racial discrimination and 12-month DSM-IV mental disorders among Asian Americans nationwide. Soc Sci Med 64:1984-1996. https://doi.org/10.1016/j. socscimed.2007.02.013

66. Kay SR, Fiszbein A, Opler LA (1987) The Positive and Negative Syndrome Scale (PANSS) for schizophrenia. Schizophr Bull 13:261-276. https://doi.org/10.1093/schbul/13.2.261

67. Combs DR, Penn DL, Fenigstein A (2002) Ethnic differences in subclinical paranoia: an expansion of norms of the paranoia scale. Cultur Divers Ethnic Minor Psychol 8:248-256. https://doi. org/10.1037/1099-9809.8.3.248

68. Michael B, Larry V, Julian H, Hannah R (2009) Introduction to meta-analysis. Wiley, UK, p 96

69. Lewis G, Pelosi AJ, Araya R, Dunn G (1992) Measuring psychiatric disorder in the community: a standardized assessment for use by lay interviewers. Psychol Med 22:465-486

70. Francescato D, Zani B (2010) Community psychology in Europe: more needed, less wanted? J Community Appl Soc Psychol 20:445-454. https://doi.org/10.1002/casp.1066

71. Berry JW, Phinney JS, Sam DL, Vedder P (2006) Immigrant youth: acculturation, identity, and adaptation. Appl Psychol 55:303-332. https://doi.org/10.1111/j.1464-0597.2006.00256.x

72. Triana MdC, García MF (2009) Valuing diversity: a group-value approach to understanding the importance of organizational efforts to support diversity. J Organ Behav 30:941-962. https:// doi.org/10.1002/job.598

73. Stephan WG, Ybarra O, Bachman G (2006) Prejudice toward immigrants. J Appl Soc Psychol 29:2221-2237. https://doi. org/10.1111/j.1559-1816.1999.tb00107.x

74. Taylor TR, Kamarck TW, Shiffman S (2004) Validation of the Detroit Area Study Discrimination Scale in a community sample of older African American adults: the Pittsburgh healthy heart project. Int J Behav Med 11:88-94. https://doi.org/10.1207/s1532 7558ijbm1102_4
75. Modood T, Berthoud R, Lakey J, Nazroo J, Smith P, Virdee S, Beishon S (1997) Ethnic minorities in Britain: diversity and disadvantage. Policy Studies Institute, London

76. Smith P, Prior G (1997) The fourth national survey of ethnic minorities: technical report. Social and Community Planning Research, London

77. Overall JE, Gorham DR (1962) The Brief Psychiatric Rating Scale. Psychol Rep 10:799-812

78. Derogatis LR, Melisaratos N (1983) The Brief Symptom Inventory: an introductory report. Psychol Med 13:595-605

79. Smitten MHSR, Van den Brink W (1998) Composite international diagnostic interview (CIDI) Version 2.1. World Health Organization, Amsterdam

80. WHO (1990) Composite International Diagnostic Interview (CIDI) Version 1.0. World Health Organization, Geneva

81. Smeets R, Dingemans P (1993) Composite International Diagnostic Interview (CIDI) Version 1.1. World Health Organization, Amsterdam

82. Kessler RC, Üstün TB (2004) The World Mental Health (WMH) survey initiative version of the World Health Organization (WHO) Composite International Diagnostic Interview (CIDI). Int J Methods Psychiatr Res 13:93-121. https://doi.org/10.1002/mpr.168

83. Fenigstein A, Vanable PA (1992) Paranoia and selfconsciousness. J Pers Soc Psychol 62:129. https://doi. org/10.1037/0022-3514.62.1.129

84. McGuffin P, Farmer A, Harvey I (1991) A polydiagnostic application of operational criteria in studies of psychotic illness: development and reliability of the OPCRIT system. Arch Gen Psychiatry 48:764-770. https://doi.org/10.1001/archpsyc.1991.0181032008 8015

85. Combs DR, Penn DL (2004) The role of subclinical paranoia on social perception and behavior. Schizophr Res 69:93-104. https ://doi.org/10.1016/S0920-9964(03)00051-3

86. Loewy RL, Bearden CE, Johnson JK, Raine A, Cannon TD (2005) The Prodromal Questionnaire (PQ): preliminary validation of a self-report screening measure for prodromal and psychotic syndromes. Schizophr Res 79:117-125. https://doi.org/10.1016/j. schres.2005.03.007

87. Ising HK, Veling W, Loewy RL, Rietveld MW, Rietdijk J, Dragt S, Klaassen RM, Nieman DH, Wunderink L, Linszen DH, van der Gaag M (2012) The validity of the 16-item version of the Prodromal Questionnaire (PQ-16) to screen for ultra high risk of developing psychosis in the general help-seeking population. Schizophr Bull 38:1288-1296. https://doi.org/10.1093/schbul/ sbs068

88. Bebbington P, Nayani T (1995) The psychosis screening questionnaire. Int J Methods Psychiatr Res 5:11-19

89. McGlashan T, Walsh B, Woods S (2010) The psychosis-risk syndrome: handbook for diagnosis and follow-up. Oxford University Press, New York

90. WHO (1994) Schedules for clinical assessment in neuropsychiatry: manual. World Health Organization, Geneva

91. Freeman D (2007) Suspicious minds: the psychology of persecutory delusions. Clin Psychol Rev 27:425-457. https://doi. org/10.1016/j.cpr.2006.10.004

92. Spitzer R, Williams J, Gibbon M, First M (1987) Structured Clinical Interview for DSM-III-R (SCID). New York State Psychiatric Institute, Biometrics Research, New York

93. Bhugra D, Kamaldeep B, Mallett R, Desai M, Singh J, Leff J (1999) Cultural identity and its measurement: a questionnaire for Asians. Int Rev Psychiatry 11:244-249. https://doi. org/10.1080/09540269974438

94. Williams DR, Yu Y, Jackson JS, Anderson NB (1997) Racial differences in physical and mental health socio-economic status, stress and discrimination. J Health Psychol 2:335-351. https://doi. org/10.1177/135910539700200305 
95. Krieger N, Smith K, Naishadham D, Hartman C, Barbeau EM (2005) Experiences of discrimination: validity and reliability of a self-report measure for population health research on racism and health. Soc Sci Med 61:1576-1596. https://doi.org/10.1016/j. socscimed.2005.03.006

96. Contrada RJ, Ashmore RD, Gary ML, Coups E, Egeth JD, Sewell A, Ewell K, Goyal TM, Chasse V (2001) Measures of ethnicityrelated stress: psychometric properties, ethnic group differences, and associations with well-being. J Appl Soc Psychol 31:17751820. https://doi.org/10.1111/j.1559-1816.2001.tb00205.x
97. McNeilly MD, Anderson NB, Armstead CA, Clark R, Corbett M, Robinson EL, Pieper CF, Lepisto EM (1996) The Perceived Racism Scale: a multidimensional assessment of the experience of white racism among African Americans. Ethn Dis 6:154-166

98. Brewster ME, Velez B, DeBlaere C, Moradi B (2012) Transgender individuals' workplace experiences: the applicability of sexual minority measures and models. J Couns Psychol 59:60-70. https ://doi.org/10.1037/a0025206 